\title{
Employee Use of a Wireless Physical Activity Tracker Within Two Incentive Designs at One Company
}

\author{
Gregory J. Norman, PhD, ${ }^{1}$ Kevin J. Heltemes, MPH, Debi Heck, MA, and Mary Jane Osmick, MD
}

\begin{abstract}
Physical activity provides numerous health benefits, including reducing risk factors that contribute to the leading causes of morbidity and mortality. Many employers offer incentives to employees to motivate engagement in wellness program activities. Two incentive designs to reward employees for achieving step goals were evaluated. This study used a retrospective design and the study population consisted of benefit-eligible employees at American Specialty Health ages 18 to 65 years who completed a health assessment and biometric screening during $2011(\mathrm{~N}=396)$ or $2012(\mathrm{~N}=500)$. A total of 320 employees participated in both years. During 2011, the incentive goal was 500,000 steps per quarter. By comparison, a 3-tier step goal plan was implemented in 2012 (ie, 400,000; 650,000; or 900,000 steps/quarter). The prevalence of participants in the step program was $64.7 \%$ in 2011 and $72.8 \%$ in 2012. The percentage of employees who reached at least 1 quarterly incentive increased from $36.3 \%$ in 2011 to $51.4 \%$ in 2012. Average steps/day was higher in 2012 (mean $[\mathrm{M}]=3573$, standard deviation $[\mathrm{SD}]=3010)$ compared to the same employees in $2011(\mathrm{M}=2817, \mathrm{SD}=2654)(P<.001)$. The findings suggest that a tiered incentive design may be an effective population approach to engage employees in physical activity. A multitier incentive design offers participants choices for goal setting and may help shape behavior toward what may be perceived as a difficult goal to achieve. (Population Health Management 2016;19:88-94)
\end{abstract}

\section{Introduction}

$\mathbf{E}$ NGAGING IN REgUlar PHYSICAL ACTIVITY (PA) is essential to overall health. ${ }^{1}$ PA provides numerous benefits, including reducing risk factors that contribute to the leading causes of morbidity and mortality such as heart disease, type 2 diabetes, depression, certain cancers, and high blood pressure. ${ }^{1,2}$ Current public health recommendations call for 10,000 steps/day for able bodied adults.

Despite the importance of PA to health, less than half of adult Americans meet national PA guidelines, ${ }^{3-5}$ a trend also seen in many countries worldwide. ${ }^{6}$ Therefore, increasing PA levels is a leading public health priority. ${ }^{7}$ Using objective sensor-based PA monitors provides an easy way to track and improve PA behavior. ${ }^{8,9}$ Pedometers and other motion tracking devices are simple and convenient to use and can be integrated easily within the daily lives of most individuals. The data uploaded from a wireless tracking device can be processed and displayed on a Web site or mobile application, providing feedback to the user. Wireless trackers automate and digitize data capture, which is called "passive measurement," removing the user burden of manually logging and uploading data.

Pedometers have been used in intervention programs to measure activity and help motivate increased PA levels. ${ }^{9}$ Numerous studies have found that pedometers are an effective tool for increasing physical activity in adults and youths. 9,10 Intervention and observational studies have indicated that using pedometers can lead to a daily increase of approximately 2000 steps $/$ day $^{9}$ and moderate weight loss. ${ }^{11}$ Pedometer interventions are more effective when used in conjunction with a self-tracking program (eg, daily step diary), goal setting tied to daily step counts, and when study participants are mostly sedentary at the onset of the intervention.

Many employers offer incentives (eg, gift cards, cash, prizes, reduced medical premiums) to their employees to motivate engagement in wellness program activities such as achieving step goals measured with wireless tracking devices. The theory behind extrinsic motivators, such as financial incentives to motivate employees to engage in wellness activities, is that they help people make better choices without actually limiting those choices. ${ }^{12,13}$ Extrinsic incentives

\footnotetext{
${ }^{1}$ American Specialty Health, San Diego, California.

(C) The Author(s) 2015; Published by Mary Ann Liebert, Inc. This Open Access article is distributed under the terms of the Creative Commons Attribution Noncommercial License (http://creativecommons.org/licenses/by-nc/4.0/) which permits any noncommercial use, distribution, and reproduction in any medium, provided the original author(s) and the source are credited.
} 
motivate behavior by making it easier (ie, more valued, preferred) for people to choose short-term actions that are consistent with their own long-term interests (eg, living healthy, living without chronic diseases). ${ }^{12}$

Basic behavior principles of reinforcement contingencies posit that experiencing the reward stimulus-response relationship creates a positive feedback loop, which strengthens when rewards are received. The target action (the response) must be perceived to be a reachable and realistic goal relative to the value of the incentive (the stimulus). If the target action is perceived as too difficult or costly, then one will not be motivated to achieve the goal and will not experience the reward. In addition, the shorter the time elapsed from the targeted action to receipt of the incentive, the stronger the stimulus-response relationship. Successful goal setting to motivate behavior involves determining a balance between an individual's ability and the difficulty of the task. As a result, offering multiple goal choices to a population, rather than 1 fixed goal, should increase engagement in order to achieve the reward. The reward stimulus-response relationship is the fundamental component that defines the incentive design.

Examining how health-related incentive designs work in practice is critical to informing best practices. ${ }^{14}$ The purpose of the present study was to examine 2 incentive plans designed to reward employees for achieving a specified number of steps measured with a wireless activity tracker. The 2 incentive plans were offered consecutively over 2 benefit period years at the same company. The first incentive plan offered a $\$ 100$ incentive each quarter to employees who accumulated at least 500,000 steps. The following year (2012) the incentive plan was changed to a 3-tier design wherein each quarter employees were rewarded $\$ 100$ for accumulating 400,000 steps, $\$ 125$ for accumulating 650,000 steps, or $\$ 150$ for accumulating 900,000 steps.

The aims of this study were to: (1) identify the prevalence of active employees (ie, $\geq 5000$ steps per day), (2) evaluate the profile of an ActiPed user (ie, demographics), (3) compare the rate of achieving quarterly incentive rewards between the 2 incentive plan designs, (4) evaluate the persistence of those achieving the step threshold by incentive plan design, and (5) identify predictors of active and light ActiPed use. It was hypothesized that a greater proportion of employees would engage in the 3-tiered incentive design and more employees would receive incentive rewards compared to the single-tier incentive design.

\section{Methods}

\section{Participants}

Data were derived from employees of American Specialty Health (ASH), a company that provides specialty health care management, population health management, and fitness programs to health plans, employer groups, and insurance carriers. All ASH employees were eligible to participate in the company's health and wellness program, called Healthyroads. Two consecutive program years were compared, with the 2011 year running from October 1, 2010, to September 30, 2011, and the 2012 year running from October 1 , 2011, to September 30, 2012.

There were 568 entirely benefit-eligible employees during 2011 and 699 during 2012. Entirely benefit eligible was defined as having access to Healthyroads wellness benefits throughout the entire year. The current study had a retrospective design and the study population consisted of entirely benefits-eligible ASH employees ages 18 to 65 years who completed a health assessment (HA) and biometric screening during $2011(\mathrm{~N}=396)$ or $2012(\mathrm{~N}=500)$. A total of $320 \mathrm{em}-$ ployees were employed throughout 2011 and 2012. The study population was identified from employee eligibility records.

\section{Wellness program and incentive design}

Employees received their health and wellness program benefit through Healthyroads (a subsidiary of American Specialty Health, Inc.). The program included HA, biometric screenings, telephonic coaching, incentive tracking, and online educational materials and resources. Employees could participate in the step incentive program and other Healthyroads components regardless of whether or not they received their medical benefits through ASH.

Each benefit year had a different incentive design. In 2011, the incentive threshold for receiving a reward was 500,000 steps per quarter and the monetary reward was a $\$ 100$ gift card. Thus, an employee could receive up to $\$ 400$ over the 2011 benefit year. In 2012, a 3-tier threshold for receiving the incentive was implemented. If employees achieved 400,000 steps in a quarter (tier 1), they received a $\$ 100$ gift card; those achieving 650,000 steps in a quarter (tier 2) received a $\$ 125$ gift card; and those achieving 900,000 steps in a quarter (tier 3 ) received a $\$ 150$ gift card. In this design, employees could receive up to $\$ 600$ over the 2012 benefit year.

Once an incentive step threshold was reached, employees requested their gift card on the Healthyroads.com Web site. Gift cards were received by mail, usually within 3 weeks of the request.

\section{Measures}

Participant's sex and age as of January 1 for each incentive year (ie, 2011, 2012) were determined from company benefit eligibility records. Age was dichotomized into 18 to 44 and 45 to 65 years old. Additional demographic information was obtained from the HA including education level, job tenure, job type, income, and marital status.

The Healthyroads HA was completed during the month of November in each incentive year and measured lifestyle risks including sedentary behavior, poor diet, high stress, and tobacco use. Sedentary was defined as $\leq 10$ minutes of moderate exercise per week and no minutes of vigorous exercise per week. Poor diet was defined as $\leq 1$ serving per day of fruit, vegetable, or grain. High stress was defined as endorsing a level 8 or higher out of 10 for health-, home-, or work-related stress. Tobacco use was assessed by asking, "Are you currently using tobacco?"

Biometric screenings were conducted at the worksite by an independent laboratory. The screenings included a fasting venipuncture blood draw for lipid profile and glucose, and a blood pressure reading.

Employees' activity level was recorded through the ActiPed wireless step tracker (Fitlinxx Inc., Boston, MA). The tracking device is worn on the shoe and tracks steps using an accelerometer. The stored step count data are transmitted wirelessly to Fitlinxx when the device comes into range of a Remote Access Point antenna, which are located throughout the ASH company buildings. Data are transferred through an 
Application Programming Interface to Healthyroads.com, where employees can view their step counts on a dashboard that displays progress toward the incentive step threshold.

The primary outcome was ActiPed use, categorized as active, light, and nonuser. An active user was defined as averaging 5000 or more steps per day. A light user averaged between 1 and 4999 steps per day. A nonuser was someone who did not use an ActiPed.

\section{Statistical analysis}

Chi-square $\left(\chi^{2}\right)$ tests were used to assess the association of categorical variables with level of ActiPed use. Multinomial logistic regression was used to evaluate predictors of ActiPed use. For the multivariate model, covariates $(P<.20)$ were entered into the final model to assess potential confounding. A general linear mixed model was used to compare the effect of the incentive design (ie, year) on total number of quarterly incentive step thresholds met. The mixed model accounted for some participants having data in 2011 and 2012. All tests were 2-tailed, and a $P$ value of $<.05$ determined statistical significance. All statistical analyses were conducted using SAS software, version 9.3 (SAS Institute Inc., Cary, NC).

\section{Results}

\section{Demographic characteristics}

The data set was comprised of 896 records from 576 individual employees, 396 of whom completed an HA and biometric screening in 2011 and 500 of whom completed these activities in 2012. A total of 320 employees completed activities in both 2011 and 2012 .

During $2011,35.4 \%$ of the study population were categorized as ActiPed nonusers. In contrast, $27.2 \%$ of the study population in 2012 were categorized as ActiPed nonusers (Table 1). Active ActiPed users had higher engagement in coaching; a higher proportion earned an income between $\$ 30,000$ to $\$ 85,000$; and a lower proportion had high stress compared to light users or nonusers during 2011 (data not shown). A higher proportion of active ActiPed users had a lower education level and reported less stress compared to light or nonusers during 2012 (data not shown).

\section{Change in incentive step threshold}

Table 2 shows the proportion of employees meeting a quarterly incentive step threshold by incentive year. The incentive year $(P<.001)$ and quarter of the year $(P<.05)$ were significant predictors for achieving a quarterly incentive step threshold. Specifically, employees in 2012 were significantly more likely to achieve a quarterly incentive step threshold when compared to 2011 (adjusted odds ratio $[\mathrm{AOR}]=2.13,95 \%$ confidence interval $[\mathrm{CI}]$ : 1.80, 2.52). Employees were significantly more likely to achieve the second quarter incentive step threshold compared to the fourth quarter $(\mathrm{AOR}=1.14,95 \% \mathrm{CI}: 1.02,1.28)$. The interaction of quarterly by year incentive design was not significant.

Overall, 36.3\% $(n=144)$ of employees reached at least 1 quarterly incentive in 2011 , while $51.4 \%(n=257)$ of employees reached at least 1 quarterly incentive in 2012, which is a $42 \%$ relative increase from 2011 to 2012 (Table 3). Similarly, among the cohort of 320 employees, the study
Table 1. Characteristics of Employees By InCENTIVE Design Year

\begin{tabular}{|c|c|c|c|c|}
\hline \multirow[b]{2}{*}{ Characteristics } & \multicolumn{2}{|c|}{$\begin{array}{c}2011 \\
(N=396)\end{array}$} & \multicolumn{2}{|c|}{$\begin{array}{c}2012 \\
(N=500)\end{array}$} \\
\hline & $N$ & $(\%)$ & $N$ & $(\%)$ \\
\hline \multicolumn{5}{|l|}{ Level of Actiped use } \\
\hline Active user & 123 & $(31.1)$ & 158 & $(31.6)$ \\
\hline Light user & 133 & $(33.6)$ & 206 & $(41.2)$ \\
\hline Nonuser & 140 & (35.4) & 136 & $(27.2)$ \\
\hline \multicolumn{5}{|l|}{ Age group } \\
\hline $18-45$ & 293 & $(74.0)$ & 365 & $(73.0)$ \\
\hline $46-65$ & 103 & $(26.0)$ & 135 & $(27.0)$ \\
\hline \multicolumn{5}{|l|}{ Sex } \\
\hline Male & 118 & $(29.8)$ & 158 & $(31.6)$ \\
\hline Female & 278 & $(70.2)$ & 342 & $(68.4)$ \\
\hline \multicolumn{5}{|l|}{ Engaged in coaching } \\
\hline Yes & 36 & $(9.1)$ & 45 & $(9.0)$ \\
\hline No & 360 & $(90.9)$ & 455 & $(91.0)$ \\
\hline \multicolumn{5}{|l|}{ Education } \\
\hline High school or less & 28 & $(7.1)$ & 32 & $(6.4)$ \\
\hline Some college & 131 & $(33.1)$ & 184 & $(36.8)$ \\
\hline Bachelor's or higher & 237 & $(59.9)$ & 284 & $(56.8)$ \\
\hline \multicolumn{5}{|l|}{ Job tenure } \\
\hline$<2$ years & 45 & (11.4) & 115 & $(23.0)$ \\
\hline 2 to 5 years & 135 & (34.1) & 134 & $(26.8)$ \\
\hline$>5$ years & 216 & $(54.6)$ & 251 & $(50.2)$ \\
\hline \multicolumn{5}{|l|}{ Income } \\
\hline$\leq \$ 30,000$ & 33 & $(10.3)$ & 65 & $(16.1)$ \\
\hline$\$ 30,001$ to $\$ 60,000$ & 135 & $(42.3)$ & 159 & $(39.5)$ \\
\hline$\$ 60,001$ to $\$ 85,000$ & 54 & (16.9) & 55 & $(13.7)$ \\
\hline$>\$ 85,000$ & 97 & $(30.4)$ & 124 & $(30.8)$ \\
\hline \multicolumn{5}{|l|}{ Job category } \\
\hline Professional & 164 & $(41.4)$ & 197 & $(39.4)$ \\
\hline Managerial & 75 & (18.9) & 95 & $(19.0)$ \\
\hline Other & 157 & $(39.7)$ & 208 & $(41.6)$ \\
\hline \multicolumn{5}{|l|}{ Marital status } \\
\hline Married & 211 & $(53.3)$ & 259 & $(51.8)$ \\
\hline Not married & 185 & $(46.7)$ & 241 & $(48.2)$ \\
\hline \multicolumn{5}{|l|}{ Activity high risk } \\
\hline Yes & 82 & $(20.7)$ & 113 & $(22.6)$ \\
\hline No & 314 & (79.3) & 387 & $(77.4)$ \\
\hline \multicolumn{5}{|l|}{ Diet high risk } \\
\hline Yes & 148 & $(37.4)$ & 196 & $(39.2)$ \\
\hline No & 248 & $(62.6)$ & 304 & $(60.8)$ \\
\hline \multicolumn{5}{|l|}{ Stress high risk } \\
\hline Yes & 107 & $(27.0)$ & 138 & $(27.6)$ \\
\hline No & 289 & (73.0) & 362 & $(72.4)$ \\
\hline \multicolumn{5}{|l|}{ Tobacco high risk } \\
\hline Yes & 16 & $(4.0)$ & 16 & $(3.2)$ \\
\hline No & 380 & (96.0) & 484 & $(96.8)$ \\
\hline \multicolumn{5}{|l|}{ High blood pressure } \\
\hline Yes & 14 & $(3.5)$ & 18 & $(3.6)$ \\
\hline No & 382 & $(96.5)$ & 482 & $(96.4)$ \\
\hline \multicolumn{5}{|l|}{ High cholesterol } \\
\hline Yes & 26 & $(6.7)$ & 35 & $(7.0)$ \\
\hline No & 362 & (93.3) & 462 & $(93.0)$ \\
\hline \multicolumn{5}{|l|}{ High glucose } \\
\hline Yes & 9 & $(2.3)$ & 13 & $(2.7)$ \\
\hline No & 375 & (97.7) & 478 & $(97.4)$ \\
\hline
\end{tabular}

Note: Active users were defined as those with at least 5000 steps per day. Light users were defined as those with 1 to 4999 steps per day. Nonusers were the reference group. 
Table 2. Employees Achieving Quarterly Step Thresholds Between the 2011 and 2012 InCENTIVE Plan Designs

\begin{tabular}{|c|c|c|c|c|c|c|c|c|}
\hline \multirow[b]{3}{*}{ Level of incentive ${ }^{\mathrm{a}}$} & \multicolumn{8}{|c|}{ Year Quarters } \\
\hline & \multicolumn{2}{|c|}{$Q 1$} & \multicolumn{2}{|c|}{$Q 2$} & \multicolumn{2}{|c|}{$Q 3$} & \multicolumn{2}{|c|}{$Q^{4}$} \\
\hline & $N$ & $(\%)$ & $N$ & $(\%)$ & $N$ & $(\%)$ & $N$ & (\%) \\
\hline 2011 Met incentive $(n=396)$ & 96 & $(24.2)$ & 114 & $(28.7)$ & 104 & $(26.2)$ & 92 & $(23.2)$ \\
\hline 2012 Met incentive $(n=500)$ & 188 & $(37.5)$ & 210 & $(42.0)$ & 208 & $(41.6)$ & 206 & $(41.2)$ \\
\hline Met tier 1 & 116 & $(23.1)$ & 140 & $(28.0)$ & 143 & (28.6) & 151 & $(30.2)$ \\
\hline Met tier 2 & 46 & $(9.2)$ & 37 & (7.4) & 41 & $(8.2)$ & 34 & $(6.8)$ \\
\hline Met tier 3 & 26 & $(5.2)$ & 33 & $(6.6)$ & 24 & $(4.8)$ & 21 & (4.2) \\
\hline Overall met incentive (2011-2012) & 284 & (31.7) & 324 & $(36.2)$ & 312 & $(34.8)$ & 298 & $(33.3)$ \\
\hline
\end{tabular}

Q, quarter

Note: During 2011, the step threshold for the incentive was 500,000 steps per quarter. During 2012, there was a 3-tier step threshold of $400,000 / 650,000 / 900,000$ steps per quarter.

${ }^{a}$ Incentive year $(P<.001)$ and incentive quarter $(P<.05)$ were significant predictors of meeting a quarterly incentive step threshold.

found that $37.2 \%(n=119)$ met a quarterly incentive in 2011 and $55.0 \%(\mathrm{n}=176)$ met a quarterly incentive in 2012 , a $47.8 \%$ relative increase. A McNemar's test showed this change in the cohort from 2011 to 2012 was statistically significant (odds ratio $=6.18,95 \% \mathrm{CI}: 3.27,11.69$ ).

In all, $13.6 \%(54 / 396)$ of employees met the incentive step threshold for all 4 quarters in 2011, whereas $28.4 \%$ of employees met their incentive all 4 quarters in 2012 (Table 3). The general linear mixed-model test showed the incentive design (ie, year) was a significant predictor of the number of quarterly step thresholds achieved $(\beta=.64, P<.001)$, and 2012 had a higher average number of quarterly step thresholds achieved compared to 2011. A paired sample $t$ test revealed that the average steps per day was significantly higher for employees in 2012 (mean [M] =3573, standard deviation $[\mathrm{SD}]=3010)$ compared to the same employees in 2011 $(\mathrm{M}=2817, \mathrm{SD}=2654)(\mathrm{t}(320)=5.78, P<.001)$.

An additional sensitivity test was conducted to determine if the higher proportion achieving an incentive in 2012 compared to 2011 was simply a function of lowering the step count threshold from 500,000 to 400,000 , rather than offering a multitiered incentive. In all, 53 employees were identified in 2011 who reached 400,000 steps but not

Table 3. Distribution of Total Quarters Employees Met Incentive Step Goal by Year

\begin{tabular}{|c|c|c|c|c|c|}
\hline \multirow[b]{2}{*}{ Quarterly incentives } & \multicolumn{2}{|c|}{$\begin{array}{c}2011 \\
(N=396)\end{array}$} & \multicolumn{2}{|c|}{$\begin{array}{c}2012 \\
(N=500)\end{array}$} & \multirow[b]{2}{*}{$\mathrm{P}$ value } \\
\hline & $N$ & $(\%)$ & $N$ & $(\%)$ & \\
\hline $\begin{array}{l}\text { Quarterly incentives } \\
\text { met, mean (SD) }\end{array}$ & 1.03 & $(1.51)$ & 1.62 & $(1.76)$ & $<.001$ \\
\hline \multicolumn{6}{|c|}{ Total quarters meeting incentive } \\
\hline 0 & 252 & $(63.6)$ & 243 & $(48.6)$ & \\
\hline 1 & 23 & $(5.8)$ & 32 & $(6.4)$ & \\
\hline 2 & 34 & $(8.6)$ & 37 & $(7.4)$ & \\
\hline 3 & 33 & $(8.3)$ & 46 & $(9.2)$ & \\
\hline 4 & 54 & (13.6) & 142 & $(28.4)$ & \\
\hline
\end{tabular}

SD, standard deviation.

Note: Incentive year was a significant predictor of the number of quarterly step thresholds achieved $(\beta=-.64, P<.001)$.
500,000 steps (needed to receive the incentive) in at least 1 quarter. The direction of the results remained the same, with employees reaching the 400,000 step threshold an average of $1.18(\mathrm{SD}=1.66)$ quarters in 2011 , compared to an average of $1.62(\mathrm{SD}=1.76)$ quarters in $2012(P<.001)$. Similarly, applying the 400,000 step threshold to 2011 resulted in $20.7 \%$ reaching the threshold in all 4 quarters, compared to $28.4 \%$ of employees in 2012.

\section{Regression analysis evaluating predictors of ActiPed use}

Table 4 presents multinomial logistic regression models evaluating predictors of ActiPed use (light and active users) in 2011 and 2012, with nonusers as the reference category. For the incentive year 2011 and after adjusting for covariates, the odds of coaching participants being active ActiPed users compared to nonusers were 3.3 times higher than noncoaching participants. After adjusting for covariates, members with household income of $\$ 60,001$ to $\$ 85,000$ were 7 times as likely to be active ActiPed users rather than nonusers, compared to those with an income of $\$ 30,000$ or less. Similarly, after adjusting for covariates, members with a household income of $\$ 30,001$ to $\$ 60,000$ were 4 times as likely to be active users rather than nonusers, compared to individuals with an income of $\$ 30,000$ or less.

For the incentive year 2012 and after adjusting for covariates, members with high stress were nearly 2 times less likely to be active users compared to nonusers, than those without high stress. In addition, those holding employment for 2 to 5 years were about 2 times less likely to be an active user or a light user, compared to employees who were with the company for less than 2 years (Table 4).

\section{Discussion}

The study results suggest an incentive design with multiple incentive tier goals was associated with greater program participation, a higher proportion of participants receiving rewards, and more physical activity compared to an incentive design with a single threshold goal. The first study hypothesis was supported: A greater proportion of employees engaged in the 3-tier incentive design compared to the 1 -tier design, a $12.5 \%$ relative increase. This change 
Table 4. Regression Analysis Identifying Predictors of Employee Active and Light ActiPed Use

\begin{tabular}{|c|c|c|c|c|c|c|c|c|}
\hline \multirow[b]{3}{*}{ Correlates } & \multicolumn{4}{|c|}{$\begin{array}{c}2011 \\
(N=396)\end{array}$} & \multicolumn{4}{|c|}{$\begin{array}{c}2012 \\
(N=500)\end{array}$} \\
\hline & \multicolumn{2}{|c|}{ Active users } & \multicolumn{2}{|c|}{ Light users } & \multicolumn{2}{|c|}{ Active users } & \multicolumn{2}{|c|}{ Light users } \\
\hline & $A O R$ & $(95 \% C I)$ & $A O R$ & $(95 \% C I)$ & $A O R$ & $(95 \% C I)$ & $A O R$ & $(95 \% C I)$ \\
\hline Engaged in coaching & 3.30 & $(1.16,9.40)$ & 2.13 & $(0.72,6.30)$ & & & & \\
\hline $\begin{array}{l}\text { Sex } \\
\quad \text { Male } \\
\text { Female }\end{array}$ & 1.68 & $(0.88,3.21)$ & 1.16 & $(0.61,2.21)$ & 1.03 & $(0.62,1.70)$ & 0.73 & $(0.45,1.20)$ \\
\hline $\begin{array}{l}\text { Education } \\
\text { Bachelor's degree or higher } \\
\text { Some college } \\
\text { High school or less }\end{array}$ & $\begin{array}{l}2.58 \\
2.74\end{array}$ & $\begin{array}{l}(0.79,8.48) \\
(0.81,9.24)\end{array}$ & $\begin{array}{l}1.90 \\
2.98\end{array}$ & $\begin{array}{l}(0.62,5.82) \\
(0.98,9.06)\end{array}$ & $\begin{array}{l}0.59 \\
0.45\end{array}$ & $\begin{array}{l}(0.23,1.54) \\
(0.16,1.22)\end{array}$ & $\begin{array}{l}0.88 \\
1.28\end{array}$ & $\begin{array}{l}(0.32,2.44) \\
(0.45,3.65)\end{array}$ \\
\hline $\begin{array}{l}\text { Income } \\
\quad>\$ 85,000 \\
\$ 60,001 \text { to } \$ 85,000 \\
\$ 30,001 \text { to } \$ 60,000 \\
\leq \$ 30,000\end{array}$ & $\begin{array}{l}2.70 \\
7.04 \\
3.91\end{array}$ & $\begin{array}{l}(0.70,10.40) \\
(1.75,28.30) \\
(1.13,13.46)\end{array}$ & $\begin{array}{l}1.57 \\
2.47 \\
1.04\end{array}$ & $\begin{array}{l}(0.55,4.44) \\
(0.82,7.45) \\
(0.42,2.58)\end{array}$ & & & & \\
\hline $\begin{array}{l}\text { Job category } \\
\text { Professional } \\
\text { Other } \\
\text { Managerial }\end{array}$ & $\begin{array}{l}0.78 \\
0.87\end{array}$ & $\begin{array}{l}(0.35,1.74) \\
(0.36,2.11)\end{array}$ & $\begin{array}{l}0.68 \\
1.12\end{array}$ & $\begin{array}{l}(0.30,1.51) \\
(0.48,2.66)\end{array}$ & & & & \\
\hline $\begin{array}{l}\text { Job tenure } \\
>5 \text { years } \\
2 \text { to } 5 \text { years } \\
<2 \text { years }\end{array}$ & & & & & $\begin{array}{l}0.78 \\
0.45\end{array}$ & $\begin{array}{l}(0.41,1.45) \\
(0.23,0.89)\end{array}$ & $\begin{array}{l}0.73 \\
0.51\end{array}$ & $\begin{array}{l}(0.41,1.33) \\
(0.27,0.96)\end{array}$ \\
\hline $\begin{array}{l}\text { Marital status } \\
\text { Married } \\
\text { Not married }\end{array}$ & & & & & 1.39 & $(0.85,2.26)$ & 1.22 & $(0.77,1.93)$ \\
\hline $\begin{array}{l}\text { Stress high risk } \\
\quad \text { Yes }\end{array}$ & 0.53 & $(0.27,1.02)$ & 0.54 & $(0.29,1.01)$ & 0.53 & $(0.31,0.92)$ & 0.89 & $(0.55,1.45)$ \\
\hline $\begin{array}{l}\text { Activity high risk } \\
\text { Yes }\end{array}$ & & & & & 0.80 & $(0.47,1.38)$ & 0.62 & $(0.37,1.05)$ \\
\hline
\end{tabular}

AOR, adjusted odds ratio; CI, confidence interval

Note: Active users were defined as those with at least 5000 steps per day. Light users were defined as those with 1 to 4999 steps per day. Nonusers were the reference group.

was mainly driven by a higher percentage of light users in 2012 compared to 2011, suggesting the tier 1 goal in the 2012 design was the appropriate balance between ability and task difficulty for many employees. ${ }^{15}$

The second study hypothesis also was supported: More employees received incentive rewards in the 3-tier incentive plan compared to the single-tier plan. There was a $42 \%$ increase in the number of employees who reached at least 1 quarterly incentive goal from 2011 to 2012. In addition, more than twice as many employees received a reward in all 4 quarters of 2012 compared to employees in 2011. An important aspect of strengthening a habit and building selfefficacy is for individuals to experience successes and receive rewards for intermittent goals. ${ }^{16,17}$ The 3-tier design made it easier for individuals to earn a quarterly reward. This may have helped encourage employees to find additional ways to achieve more steps/day in an effort to work toward achieving the second or third tier goals.

Among employees who participated in both incentive designs, a higher average number of steps per day were found in 2012 compared to 2011. Lowering the minimum step goal from 500,000 to 400,000 steps/quarter did not decrease, but actually increased the average number of daily steps employees achieved. The combination of a lower initial step goal along with additional step goal tiers offered sedentary people a reasonable goal, while tiers 2 and 3 provided active individuals a relevant goal to work toward. With less than 5000 steps/day being considered sedentary and 10,000 steps/day being considered the recommended guideline, ${ }^{18}$ a tiered set of step goals can help shape employees' behavior toward the recommended guideline. The tier 3 goal of 900,000 steps/quarter was equivalent to 10,000 steps/day. Over time, an employer's incentive program could gradually increase the minimum step goal to shape employees' behavior toward the 10,000 steps/day goal.

\section{Theoretical mechanisms of engagement}

Behavioral economics posits that the choice of alternative behaviors depends on their cost. ${ }^{19}$ The choice of being physically active as an alternative to being sedentary is responsive to cost and can be influenced by adding an external 
incentive to the behavior to influence choice. The incentives in the wellness program were designed to increase the likelihood of choosing to be physically active over being sedentary. The 2011 reward equated to earning $\$ .01$ for every 50 steps if 500,000 steps were achieved in the quarter. The 2012 reward equated to $\$ .01$ for every 40 steps, which made achieving the reward $20 \%$ easier and increased the value of each step taken, compared to 2011. Those employed at the company in both 2011 and 2012 likely recognized this change in the value of the reward equating to a reduced behavioral cost of accumulating steps. The change in the cost of physical activity explains why a higher proportion of employees participated in 2012 compared to 2011.

Interestingly, tiers 2 and 3 in the 2012 incentive design equated to a higher behavioral cost task with $\$ .01$ earned for every 100 steps taken. However, employees who achieved the tier 1 goal now had a "stretch goal" to work toward. It also may have created a mental "anchor" for motivating employees to achieve "at least" tier 1 because that was the easiest of the 3 tiers. "Anchoring" is a behavioral economics concept whereby an initial piece of information is used to make subsequent judgments. In this case, the 2011 step goal and the 2012 tier 2 and tier 3 step goals made perception of the 2012 tier 1 step goal as relatively more reasonable to achieve.

In $2012,56 \%$ made it only to tier 1 , while $24.5 \%$ made it to tier 2 in at least one quarter and $19.5 \%$ of users made it to tier 3 in at least 1 quarter. These percentages indicate that all 3 tiers were relevant to at least some employees in the organization and gave employees options for which tiers to try to achieve. Relevant goals are important to the individual and are critical for maintaining commitment to a goal. ${ }^{14,15} \mathrm{Mer}$ rick and colleagues outlined factors to consider to further tailor incentives and Adams and colleagues demonstrated a systematic method to individualize goal setting based on using a percentile value from previous behavior. ${ }^{14,15}$ Both person-centered incentives and person-centered goals should promote increased participation and improved outcomes over interventions that offer less choice to individuals. ${ }^{14}$

The 3-tier incentive design also may have helped employees to set shorter term and longer term goals during the year. For example, an employee can decide to set a goal of reaching tier 1 in the first quarter of the year and then, if that goal is met, set tier 2 as a goal for the second quarter. Because the second quarter began in January, the higher participation levels seen in quarter 2 of both years are likely related to the New Year's resolution phenomenon.

\section{Predictors of ActiPed use}

No clear pattern of characteristics emerged that defined active or light Actiped users compared to nonusers. Consistent with previous literature, the present study found active individuals reported lower stress. ${ }^{20}$ The direction of causality for the inverse relationship between level of stress and ActiPed use could go in either direction. Employees may feel too overwhelmed with other parts of their lives to participate in this component of a wellness program, ${ }^{21}$ particularly employees in early stages of change for physical activity. ${ }^{22}$ It also may be the case that physical activity had a positive impact on participants' stress levels. This suggests that pairing physical activity programs with stress man- agement programs might help to improve participation in physical activity.

\section{Study strengths and limitations}

A notable study strength was that the step activity program was completely voluntary in both incentive design years and was not tied to the employee's medical plan. Thus, employees could choose to participate rather than feel participation was required, which may impact motivation to incorporate physical activity into their lifestyle. ${ }^{19}$ In addition, in both years the quarterly rewards were received within a few weeks of achieving the step goal, which helped to maintain the perceived value of the reward as opposed to a delayed reward, which loses value as the time to delivery increases. The use of wireless Actiped activity trackers by employees in both years also was a study strength because employees were not burdened with manually logging steps and the Actiped provided an "objective" measure of employees' step count.

A limitation of the current study was the observational study design from which one can only speculate about any causal inferences suggested by the findings. However, the sequential study design controlled for some confounding factors because data were derived from 1 employer with $56 \%$ of employees exposed to both incentive designs. The consistency of the findings between those employees participating in 2011 or 2012, and those employees who participated in 2011 and $2012(n=320)$ support attributing the results to the differing incentive designs rather than to different employee populations. However, one cannot rule out the possibility that part of the increase in participation from 2011 to 2012 was the result of factors other than the change in the incentive program design (eg, a coworker convinced others to participate).

The generalizability of the study findings is limited to employers with similar profiles of aggregated employee attributes. Although higher rates of engagement and physical activity levels might be expected from employees of a company in the health and wellness industry compared to the general employer population, the employee population at $\mathrm{ASH}$ was quite diverse in regard to socioeconomic status indicators, job categories, and behavior risk factors such as stress, physical activity, and diet. Because of the diverse employee characteristics, the authors believe the findings generalize beyond health-oriented companies.

\section{Conclusions}

This study found that the 3-tier incentive design was related to a higher proportion of employees using an ActiPed and more employees reaching quarterly incentive step goals compared to the single-tier incentive design. The efficacy of public health programs that use pedometers has been established, ${ }^{9,11}$ but continued research is needed to understand incentive design components that can increase initial and sustained engagement in such programs.

\section{Author Disclosure Statement}

Drs. Norman and Osmick, Mr. Heltemes, and Ms. Heck declared no conflicts of interest with respect to the research, authorship, and/or publication of this article. All authors are 
employees of American Specialty Health, Inc., and the work was done as part of their employment with American Specialty Health. The authors received no financial support for the research, authorship, and/or publication of this article.

\section{References}

1. Kruk J. Physical activity in the prevention of the most frequent chronic diseases: an analysis of the recent evidence. Asian Pac J Cancer Prev. 2007;8(3):325-338.

2. Danaei G, Ding EL, Mozaffarian D, et al. The preventable causes of death in the United States: comparative risk assessment of dietary, lifestyle, and metabolic risk factors. PLoS Med. 2009;6(4):e1000058.

3. Troiano RP, Berrigan D, Dodd KW, Mâsse LC, Tilert T, McDowell M. Physical activity in the United States measured by accelerometer. Med Sci Sports Exerc. 2008;40(1): 181-188.

4. Li C, Balluz LS, Okoro CA, et al. Surveillance of certain health behaviors and conditions among states and selected local areas-Behavioral Risk Factor Surveillance System, United States, 2009. MMWR Surveill Summ. 2011;60(9):1-12.

5. Eaton DK, Kann L, Kinchen S, et al. Youth Risk Behavior Surveillance-United States, 2011. http://www.cdc.gov/ mmwr/preview/mmwrhtml/ss6104a1.htm. Accessed June 27, 2012.

6. Knuth AG, Hallal PC. Temporal trends in physical activity: a systematic review. J Phys Act Health. 2009;6:548-559.

7. Koh HK. A 2020 vision for healthy people. N Engl J Med. 2010;362:1653-1656.

8. Tudor-Locke C, Williams JE, Reis JP, Pluto D. Utility of pedometers for assessing physical activity: convergent validity. Sports Med. 2009;32:795-808.

9. Bravata DM, Smith-Spangler C, Sundaram V, et al. Using pedometers to increase physical activity and improve health: a systematic review. JAMA. 2007;298:2296-2304.

10. Lubans DR, Morgan PJ, Tudor-Locke C. A systematic review of studies using pedometers to promote physical activity among youth. Prev Med. 2009;48:307-315.

11. Richardson CR, Newton TL, Abraham JJ, Sen A, Jimbo M, Swartz AM. A meta-analysis of pedometer-based walking interventions and weight loss. Ann Fam Med. 2008;6(1):69-77.
12. Halpern SD, Madison KM, Volpp KG. Patients as mercenaries? The ethics of using financial incentives in the war on unhealthy behaviors. Circ Cardiovasc Qual Outcomes. 2009;2:514-516.

13. Loewenstein G, Brennan T, Volpp KG. Asymmetric paternalism to improve health behaviors. JAMA. 2007;298: 2415-2417.

14. Merrick EL, Hodgkin D, Horgan CM. Incentives to shape health behaviors: how can we make them more personcentered? J Workplace Behav Health. 2014;29(1): 19-31.

15. Latham G, Locke EA. Building a practically useful theory of goal setting and task motivation. Am Psychol. 2002;57: 705-717.

16. Bandura A. Human agency in social cognitive theory. Am Psychol. 1989;44:1175-1184.

17. Adams MA, Sallis JF, Norman GJ, Hovell MF, Hekler EB, Perata E. An adaptive physical activity intervention for overweight adults: a randomized controlled trial. PLoS One. 2013;8(12):e82901.

18. Sisson SB, Camhi SM, Tudor-Locke C, Johnson WD, Katzmarzyk PT. Characteristics of step-defined physical activity categories in U.S. Adults. Am J Health Promot. 2012;26:152-159.

19. Epstein LH. Integrating theoretical approaches to promote physical activity. Am J Prev Med. 1998;15:257-265.

20. Paluska SA, Schwenk, TL. Physical activity and mental health: current concepts. Sports Med. 2000;29(3):167-180.

21. Stults-Kolehmainen MA, Sinha R. The effects of stress on physical activity and exercise. Sports Med. 2014;44(1):81-121.

22. Prochaska JO, DiClemente CC, Norcross JC. In search of how people change: applications to addictive behaviors. Am Psychol. 1992;47:1102-1111.
Address correspondence to: Gregory J. Norman, PhD Healthyroads 10221 Wateridge Circle San Diego, CA 92121

E-mail: gnorman@ucsd.edu 